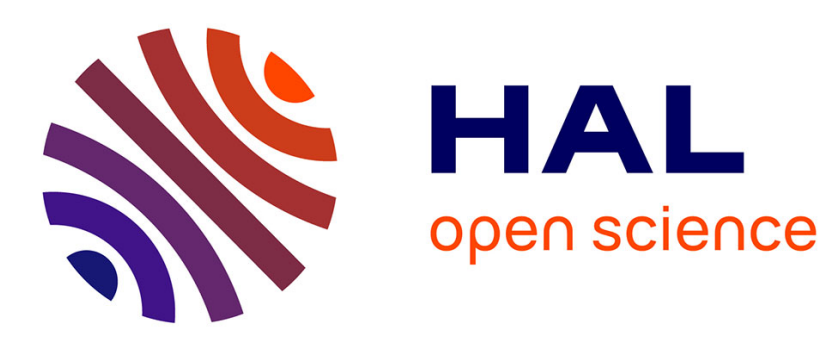

\title{
Postural- and respiratory-related activities of abdominal muscles during post-exercise hyperventilation
}

Pascal David, Jérémy Terrien, Michel Petitjean

\section{To cite this version:}

Pascal David, Jérémy Terrien, Michel Petitjean. Postural- and respiratory-related activities of abdominal muscles during post-exercise hyperventilation. Gait \& Posture, 2015, 41 (4), pp.899-904. 10.1016/j.gaitpost.2015.03.012 . hal-01136778

\section{HAL Id: hal-01136778 \\ https://hal.science/hal-01136778}

Submitted on 28 Mar 2015

HAL is a multi-disciplinary open access archive for the deposit and dissemination of scientific research documents, whether they are published or not. The documents may come from teaching and research institutions in France or abroad, or from public or private research centers.
L'archive ouverte pluridisciplinaire HAL, est destinée au dépôt et à la diffusion de documents scientifiques de niveau recherche, publiés ou non, émanant des établissements d'enseignement et de recherche français ou étrangers, des laboratoires publics ou privés. 


\section{Accepted Manuscript}

Title: Postural- and respiratory-related activities of abdominal muscles during post-exercise hyperventilation

Author: Pascal David Jérémy Terrien Michel Petitjean

PII: $\quad$ S0966-6362(15)00081-8

DOI: $\quad$ http://dx.doi.org/doi:10.1016/j.gaitpost.2015.03.012

Reference: $\quad$ GAIPOS 4449

To appear in: $\quad$ Gait \& Posture

Received date: $\quad 12-11-2014$

Revised date: 23-2-2015

Accepted date: $\quad$ 19-3-2015

Please cite this article as: David P, Terrien J, Petitjean M, Postural- and respiratoryrelated activities of abdominal muscles during post-exercise hyperventilation, Gait and Posture (2015), http://dx.doi.org/10.1016/j.gaitpost.2015.03.012

This is a PDF file of an unedited manuscript that has been accepted for publication. As a service to our customers we are providing this early version of the manuscript. The manuscript will undergo copyediting, typesetting, and review of the resulting proof before it is published in its final form. Please note that during the production process errors may be discovered which could affect the content, and all legal disclaimers that apply to the journal pertain. 


\title{
Postural- and respiratory-related activities
}

\section{of abdominal muscles during post-exercise hyperventilation}

\author{
Pascal David $^{\mathrm{a}^{*}}$, Jérémy Terrien ${ }^{\mathrm{b}}$ and Michel Petitjean ${ }^{\mathrm{a}, \mathrm{c}, \mathrm{d}}$ \\ ${ }^{a}$ Université de Versailles Saint-Quentin en Yvelines, Montigny-le-Bretonneux, France \\ ${ }^{\mathrm{b}}$ Service d'électronique, Université de Technologie de Compiègne, Compiègne, France \\ ${ }^{\mathrm{c}}$ Unité 1179 INSERM, Montigny-le-Bretonneux, France \\ ${ }^{\mathrm{d}}$ Service de Physiologie-Explorations Fonctionnelles, Hôpital Ambroise Paré, Groupe \\ Hospitalier Paris Ile-de-France Ouest, Boulogne-Billancourt, France
}

* Corresponding author: Pascal David, PhD, Research Associate, Université de Versailles

Saint-Quentin en Yvelines, Montigny le Bretonneux

E-mail address: pascal17david@gmail.com (P. David)

\section{Conflict of interest statement}

The authors declare that there is no conflict of interest.

\section{Acknowledgements}

We are grateful to the anonymous reviewer from ServiceScape for the English revision of the manuscript.

Submission type: Original Article (full paper)

Abstract word count: 196

Manuscript word count: 2,993 (excluding figures, tables, reference, and abstract)

Number of tables: 1

Number of figures: 4 


\title{
Postural- and respiratory-related activities
}

\section{of abdominal muscles during post-exercise hyperventilation}

\author{
Pascal David $^{\mathrm{a}^{*}}$, Jérémy Terrien ${ }^{\mathrm{b}}$ and Michel Petitjean ${ }^{\mathrm{a}, \mathrm{c}, \mathrm{d}}$ \\ ${ }^{a}$ Université de Versailles Saint-Quentin en Yvelines, Montigny-le-Bretonneux, France \\ ${ }^{\mathrm{b}}$ Service d'électronique, Université de Technologie de Compiègne, Compiègne, France \\ ${ }^{c}$ Unité 1179 INSERM, Montigny-le-Bretonneux, France \\ ${ }^{\mathrm{d}}$ Service de Physiologie-Explorations Fonctionnelles, Hôpital Ambroise Paré, Groupe \\ Hospitalier Paris Ile-de-France Ouest, Boulogne-Billancourt, France \\ * Corresponding author: Pascal David, PhD, Research Associate, Université de Versailles \\ Saint-Quentin en Yvelines, Montigny le Bretonneux \\ E-mail address: pascal17david@gmail.com (P. David)
}

\section{Conflict of interest statement}

The authors declare that there is no conflict of interest.

\section{Acknowledgements}

We are grateful to the anonymous reviewer from ServiceScape for the English revision of the manuscript.

Submission type: Original Article (full paper)
Abstract word count: 196
Manuscript word count: 2,993 (excluding figures, tables, reference, and abstract)
Number of tables: 1
Number of figures: 4 


\begin{abstract}
The present study focuses on the role of superficial abdominal muscles revealed by electromyographic recordings during the maintenance of a bipedal stance perturbed by postexercise hyperventilation. Twelve healthy subjects performed six 30-second postural tests: one pre-exercise test while breathing quietly, then one test every minute for the five minutes immediately following a maximum-intensity, incremental cycling exercise test. Displacement of the centre of pressure in the sagittal plane was monitored over time. Myoelectric activities of the obliquus externus (OE), obliquus internus (OI) and rectus abdominis (RA) muscles were recorded by surface electromyography (EMG). Metabolic parameters were measured with a portable telemetric device. The change in ventilatory drive induced by exercise was accompanied by a significant increase in both postural sway parameters and EMG activities. For $\mathrm{OE}$ and $\mathrm{OI}$, the increased EMG activities were prominent during expiration, whereas OI was silent during inspiration. $\mathrm{OE}$ and RA were activated during both expiration and inspiration. It is concluded that the compensation of respiratory disturbances of the erect posture appears to be less effective when minute ventilation increases. The patterns of muscle activity suggest that abdominal muscles are controlled differentially and that their functional coordination is dependent on the respiratory demand.
\end{abstract}

Keywords: Electromyography; biomechanics; postural control; respiration 


\section{Introduction}

The ability to maintain balance plays a fundamental role in motor programming. In many physical and sporting activities, this ability is considered as a key factor for supporting voluntary movement [1]. In addition to gravity and other external forces, internal forces related to voluntary movement and cardiorespiratory activities may disturb postural stability. In an upright stance at rest, it is well known that quiet breathing perturbs body balance in the sagittal and frontal planes, and that the effects of compensatory motions of the trunk and lower limbs are more pronounced in the sagittal plane [2]. When the respiratory demand increases, the deeper and faster rib cage movements lead to greater postural sways, which seem to be more compensated by the postural control system when respiration is under automatic control, suggesting the existence of functional links between respiration and postural control centres $[2,3]$.

Abdominal muscles that constitute the anterolateral wall of the abdomen contribute significantly to postural control [4]. In an upright stance, De Troyer [5] reported tonic abdominal muscle activity, reflecting the antigravitational function of these muscles. Due to their anatomical arrangement, the abdominal muscles have distinguishable actions on trunk movement, and thus, have an important role in the control and movement of the lumbar spine and pelvis [6]. In addition, abdominal muscles participate in a wide range of postural adjustments, for instance, they are activated to preserve the whole body balance in response to external biomechanical perturbations [7]. They can also be activated prior to the onset of voluntary movements to compensate predictable movement-related postural disturbances [8].

In addition to their contribution to postural activities, abdominal muscles also contribute to respiration [9]. The myoelectric activities of these muscles are reduced during quiet breathing because expiration depends primarily on the elastic recoil of the respiratory system. However, abdominal muscles become increasingly active and show phasic, 
expiratory-related activity in parallel with increasing peripheral oxygen demand due to exercise $[10,11]$. By their contraction, they contribute to the regulation of the end-expiratory lung volume and expiratory airflow, and assist inspiration by regulating the length of the diaphragm $[5,12]$. Thus, abdominal muscles are generally regarded as the principal muscles of active expiration.

Several studies have investigated the strategies used by the central nervous system (CNS) to adequately coordinate the postural and respiratory functions of abdominal muscles during daily activities [13,14]. From these studies, it seems that: (i) both postural and respiratory functions can be performed simultaneously; and (ii) the CNS seems to be able to prioritize one function over the other if necessary. In this context, high-intensity physical activity represents a physiological challenge for the CNS; it requires rapid adjustments of respiratory function essential for the maintenance of blood gas homeostasis, as well as the involvement of the postural control system to compensate for respiratory-related postural disturbances $[2,3]$. Accordingly, the aim of this study was to investigate the influence of postexercise hyperventilation on the recruitment of the abdominal muscles during standing in healthy young adults. The increased metabolic and postural sway parameters expected following a cycling exercise test $[15,16]$ should reveal the abdominal activation strategies selected by the CNS to appropriately manage postural disturbances and respiratory demand.

\subsection{Materials and Methods}

\subsection{Participants}

Twelve healthy university students participated in this study (10 males and 2 females; mean age: $20.6 \pm 1.8$ yrs; mean weight: $69.2 \pm 9 \mathrm{~kg}$; mean height: $1.7 \pm 0.1 \mathrm{~m})$. All subjects had been fully informed of the experiment's aims and procedure (in accordance with the Declaration of Helsinki) and gave their written consent. None of them had any known 
diseases or injuries that might have impaired balance or respiration. In order to evaluate the subjects' pulmonary capacity, routine spirometric tests using a Fleisch pneumotachograph (Masterlab, Jaeger, France) were performed by the same experimenter. The normality of parameters such as tidal volume $\left(\mathrm{V}_{\mathrm{T}}\right)$ or vital capacity $(\mathrm{VC})$ was judged according to the reference values proposed by the European Respiratory Society [17].

\subsection{Data collection}

A piezoelectric force plate (type 9281, Kistler AG, Winterthur, Switzerland) was used to continuously record the displacement of the centre of pressure (CoP). Since respiratory movements mainly concern the sagittal plane, we only considered the anteroposterior displacement of the $\mathrm{CoP}\left(\mathrm{CoP}_{\mathrm{A}-\mathrm{P}}\right)$. The force plate signal was sampled at $1,000 \mathrm{~Hz}$ using a $12-$ bit analogue-to-digital converter (Daq Card AI-16E-4, National Instruments, Austin, TX) and then stored on a computer for off-line processing.

Electromyographic (EMG) signals were recorded unilaterally from the right obliquus externus (OE) abdominis, right obliquus internus (OI) abdominis and right rectus abdominis (RA) muscles in a bipolar mode using two 8-mm-diameter silver chloride surface electrodes (Beckman, Fullerton, CA). Pairs of electrodes (centre-to-centre spacing: $20 \mathrm{~mm}$ ) were placed about $2 \mathrm{~cm}$ lateral to the midline and $1 \mathrm{~cm}$ above the umbilicus for the RA, $15 \mathrm{~cm}$ lateral to the umbilicus for the $\mathrm{OE}$ and $1 \mathrm{~cm}$ medial to the anterior superior iliac spine (ASIS) and beneath a line joining both ASISs for the OI, following SENIAM recommendations [18]. Impedance of the skin-electrode interface was maintained below $5 \mathrm{k} \Omega$. A ground electrode was placed over the sternum. Surface EMG electrodes were connected to a bipolar multichannel amplifier (Gould 6600, Gould Electronics, Cleveland, Ohio), with a bandwidth frequency ranging from 10 to $500 \mathrm{~Hz}$ and the gain adjusted to between 1,000 and 5,000. 
Electromyographic signals were sampled at 1,000 Hz using the 12-bit analogue-to-digital converter described above and then stored on the computer for off-line processing.

Oxygen uptake $\left(\dot{\mathrm{VO}}_{2}\right)$ was measured telemetrically using a portable gas analyser (Cosmed $\mathrm{K}_{2}$, Vacumetrics Inc., Ventura, CA). Minute ventilation ( $\mathrm{V}^{\mathrm{E}}$ ) was also measured, along with the tidal volume $\left(\mathrm{V}_{\mathrm{T}}\right)$ and breathing frequency $\left(f_{\mathrm{R}}\right)$ components. Heart rate $(\mathrm{HR})$ was obtained from a chest strap (Xtrainer Plus, Polar Electro Oy, Kempele, Finland). The respiratory signal was obtained by measuring variations in the timing of breaths via a custommade connection realized inside the Cosmed $\mathrm{K}_{2}$ portable unit. When the subject expires through the face mask, the revolutions of the turbine produce a voltage signal. Conversely, when the subject inspires, the turbine stops and leads to the cancellation of the voltage signal. The square-wave output signal was transmitted simultaneously with the $\mathrm{CoP}_{\mathrm{A}-\mathrm{P}}$ and $\mathrm{EMG}$ signals to the 12-bit analogue-to-digital converter acquisition system. The experimental set-up is illustrated in Fig. 1.

\subsection{Experimental procedure}

Subjects performed a total of 6 postural tests, each corresponding to the maintenance of a bipedal stance for $30 \mathrm{~s}$ with their eyes open. Subjects were asked to stand barefoot on the force plate, relax with their arms hanging alongside the trunk and focus on a target placed $2 \mathrm{~m}$ in front of the subject at eye level. The foot position was standardized by placing foot prints on the force plate. The foot prints were drawn so that the respective longitudinal axes formed a $30^{\circ}$ angle and intersected the force plate's anteroposterior axis, with the heels $2 \mathrm{~cm}$ apart. A reference test (pre-effort postural test) was carried out in quiet conditions prior to a maximal incremental cycling exercise (ICE) test. The exercise testing procedure has been described previously in detail [16]. Briefly, the exercise test was performed on a friction-loaded cycle ergometer (Monark 824E, Stockholm, Sweden). The increase in workload was individualized 
based on each subject's predicted maximum oxygen uptake and converted into maximum consecutive periods: a 3-min warm-up (with a workload corresponding to $20 \%$ of Wmax) and a 10-min period of incremental exercise from 20 to $100 \%$ of Wmax, with an increased workload stage every minute. Five post-effort postural tests (PEPTs) were then carried out: immediately after the ICE $\left(\mathrm{PEPT}_{0}\right)$ and during the first 30 seconds of each of the next 4 minutes $\left(\mathrm{PEPT}_{1}\right.$ to $\left.\mathrm{PEPT}_{4}\right)$.

\subsection{Data analysis}

Off-line signal processing was performed in Matlab 6.5 (The Mathworks Inc., Natick MA). The respiratory and $\mathrm{CoP}_{\mathrm{A}-\mathrm{P}}$ signals were passed through a 4th-order low-pass Butterworth filter with a cut-off frequency of $15 \mathrm{~Hz}$. Kinematics of the $\mathrm{CoP}_{\text {A-P }}$ were analyzed by computing the sway path (SP) and the mean amplitude $(\Delta \mathrm{x})$. The cardiorespiratory values were averaged every 5 seconds and stored for further analysis. For each subject, the $\mathrm{V}_{\mathrm{T}}$ to $\mathrm{VC}$ ratio was used as an index of ventilatory change. The post-processing of raw EMG data included offset correction and full-wave rectification using an absolute function. Due to the proximity of the electrode sites to the heart, the three EMG signals were passed through a 4thorder high-pass Butterworth filter with a cut-off frequency of $30 \mathrm{~Hz}$ [19]. During the postural tests, myoelectrical activities were quantified by computing the root mean square (RMS) value. The RMS values were then averaged according to the phase of the respiratory cycle and expressed as percentages of each subject's baseline values acquired during the pre-effort postural test. 


\subsection{Statistical analysis}

Data distributions were checked for normality using a Kolmogorov-Smirnov test and for equality of variance using a Fisher-Snedecor test. Non-normally distributed data underwent log-transformation. A simple analysis of variance with repeated-measures was performed on the postural test to assess the effects caused by ICE on metabolic $\left(\dot{\mathrm{V}} \mathrm{O}_{2}, \dot{\mathrm{V}} \mathrm{E}\right.$, $\mathrm{V}_{\mathrm{T}}, \mathrm{V}_{\mathrm{T}} / \mathrm{VC}, f_{\mathrm{R}}, \mathrm{HR}$ ), electromyographic (OE RMS, OI RMS, RA RMS), and postural sway (SP, $\Delta \mathrm{x}$ ) parameters. Post hoc testing using the Tukey honestly significant difference test was used to identify local differences. Differences were considered significant when $p<0.05$. Data are presented as mean \pm one standard deviation. All data analyses were performed with Statview software (SAS institute Inc, Cary, NC).

\section{Results}

\subsection{Effects of ICE on metabolic and postural parameters}

The mean maximal power output produced by the subjects at the end of ICE was 249.6 $\pm 49.9 \mathrm{~W}$. As shown in Table 1 , measurements taken at $\mathrm{PEPT}_{0}$, immediately following ICE, prompted a significant increase in all cardiorespiratory parameters $(p<0.01)$. Significant increases in postural sway parameters were also observed $(p<0.05)$. The analysis of the $\mathrm{CoP}_{\mathrm{A}-\mathrm{P}}$ signal immediately after ICE showed that $\mathrm{CoP}_{\mathrm{A}-\mathrm{P}}$ displacement was cyclical (Fig. 2). The simultaneous recording of the mechanical and respiration signals revealed displacements of $\mathrm{CoP}_{\mathrm{A}-\mathrm{P}}$ backwards during inspiration and correspondingly forwards during expiration. All cardiorespiratory and postural parameters remained significantly higher $(p<0.05) 4$ minutes after ICE, with the exception of $\Delta x$, which returned to pre-effort values two minutes after ICE.

\subsection{Abdominal muscle activities}


In comparison to reference values, ICE led to a significant $(p<0.01)$ increase in OE (+249\%), OI (+116\%) and RA (+183\%) RMS values. All myoelectric activities remained significantly higher $(p<0.01) 4$ minutes after ICE, with the exception of OI, which returned to pre-effort values one minute after ICE (Fig. 3A).

Although no phasic abdominal EMG activity was observed during the pre-effort postural test (Fig. 4A), the activity of these muscles recorded immediately after ICE clearly displayed phasic bursts, especially with OE and OI. A typical time course of respiration and abdominal EMG recordings is illustrated in Fig. 4B. From the mean patterns of EMG activity (calculated across all analogous respiratory cycles), the results showed that phasic bursts of OA and OI EMG activities occurred simultaneously with expiration (Fig. 2). From the whole group, quantification of EMG activities within the respiratory cycle revealed a significant $(p<$ 0.05) increase in RMS values for all three abdominal muscles during expiration (Fig. 3B). For OE and RA, the results also showed a significant $(p<0.05)$ increase in RMS values during inspiration, yet these increases were less pronounced, especially for $\mathrm{OE}(p<0.05)$.

\section{Discussion}

The results show that post-exercise hyperventilation in standing posture involves: (i) a periodic movement of the $\mathrm{CoP}$ that is time-locked to respiration; and (ii) different abdominal muscle activation strategies.

Abdominal muscles are thought to contribute to respiration, particularly if the oxygen demand is increased by exercise. Indeed, previous studies have reported respiratory-related abdominal muscle activity thresholds for minute ventilation equal to or greater than $40 \mathrm{~L} / \mathrm{min}$ $[10,11]$. Persistent EMG activity in abdominal muscles throughout the post-exercise recovery for minute ventilation values above $40 \mathrm{~L} / \mathrm{min}$ suggests that these muscles played an important role in respiration. Although pulmonary ventilation remained significantly higher one minute 
after ICE (60-90 litres/min), the EMG activity of OI returned to pre-effort values. Thus, our

results revealed differential activity and presumably different physiological roles of abdominal muscles during standing, as well as during respiratory muscle mass derecruitment following the onset of the post-exercise recovery. Synchronization of abdominal muscle activities with expiration leaves no doubt about the expiratory contribution of these muscles, especially OE and OI. These results are in good agreement with those obtained in previous work [12], where increases in intra-abdominal and intra-thoracic pressures at the end of expiration during heavy exercises were reported, suggesting the stiffening of the abdomen by abdominal muscle contraction.

The comparison of muscle activation patterns between abdominal muscles showed that only OE and RA were activated during inspiration. Several possible explanations could account for the selective activation of these muscles during inspiration. During high-intensity physical activity, the OE and RA muscles could be stretched with the greater excursion of the rib cage motion as attested by the backward CoP displacement and value of $\mathrm{V}_{\mathrm{T}} / \mathrm{VC}$ measured in this study, resulting in a muscle stretch reflex. Therefore, the activity of these muscles would increase during inspiration, presumably to maintain upright posture as suggested previously by Beith and Harrison [20]. Another possible explanation involves the gradual, controlled relaxation of the abdominal muscles during inspiration, known to prevent rib cage distortion and to assist diaphragmatic function by providing agonist-antagonist muscles cooperation [21]. Lastly, the increase in RA myoelectric activity observed during both inspiration and expiration could express a specific postural strategy, intended to enhance the stiffness and stability of the trunk by increasing intra-abdominal pressure [22]. The levels of activity in the OE and RA muscles, which remained significantly higher 4 minutes after ICE despite minute ventilation values below $40 \mathrm{~L} / \mathrm{min}$, suggest that their contribution was dedicated to postural regulation rather than respiratory supply. 
In healthy upright subjects at rest, the respiratory-related postural disturbances are compensated by motion of the trunk and lower limbs that are phase-locked to respiration [2]. However, the degree to which the respiratory disturbances are compensated has been shown to depend on various factors, including mobility of the postural chain [23] and low back pain [24]. Our results show that the degree of compensation also depends on the respiratory demand. Indeed, standing subjects displayed $\mathrm{CoP}_{\mathrm{A}-\mathrm{P}}$ displacements of greater amplitude, backwards during inspiration and correspondingly forwards during expiration, suggesting a reduced postural compensation for respiration when breathing at high levels of minute ventilation. These results are consistent with previous studies that report a higher coherence between respiratory movement and $\mathrm{CoP}$ displacement with increased respiration $[2,16]$. It this context, it was suggested that the lumbar spine and pelvis (for which the abdominal muscles play an important role in their control and movement [6]) are considered as a key factor for compensating for respiratory disturbances $[2,23]$. Thus, a decreased postural compensation to respiration could be due to changes affecting postural and respiratory activation of the abdominal muscles. Previous studies have shown dual modulation of trunk muscle activity with regard to respiration and posture [14,25]. Based on these studies, a lower contribution to the maintenance of posture by the $\mathrm{OE}$ and $\mathrm{OI}$ muscles immediately after the cessation of cycling exercise could account for a reduced postural compensation for respiration [2], and thus the greater postural oscillations measured in the present study.

The posturographic and EMG examinations associated with breathing pattern analysis reflect the complex and multivariate strategies used by the CNS to adequately coordinate the postural and respiratory functions of the abdominal muscles. As evidenced by the patterns of muscle activity, the present data suggest that: (i) both postural and respiratory functions can be performed simultaneously; and (ii) the CNS seems able to prioritize one function over the other when respiration increases, suggesting a selective coordination between the rhythmical 
respiratory drive and the postural drive to the abdominal muscles. This supports the

observations reported by Hodges et al. [25], Saunders et al. [14] and more recently by David et al. [3], which showed that different respiratory drives impact postural control differently, at least at the ankle level. Otherwise, if our results reinforce the existence of functional links between respiration and postural control centres, the strategies used by the CNS could also be influenced by the state of functional systems involved in the movement [26]. Reduced posturo-kinetic capacity, through physiological limitations of the coordination of the postural and respiratory functions of the trunk muscles [27], would explain the impaired mechanism of compensation for increased respiration in low back pain subjects [24]. In our study, all subjects succeeded in maintaining an upright posture despite minute ventilation values of up to $100 \mathrm{~L} / \mathrm{min}$. Their experience in various sports activities, reflecting not only greater neuromuscular control of trunk muscles [28], but also a greater ability to maintain and restore balance in challenging conditions [29], had probably improved the ability of their CNS to adequately manage respiratory drive and postural control. Insofar as effects of respiration on postural sway increase with age and disease [30], the present results have clinical implications, suggesting that interventions such as abdominal wall muscle training may increase compensatory abilities in posturally unstable patients. Moreover, rehabilitation programs aimed at improving the motor control of trunk stability must be coordinated with hyperventilation challenges.

In conclusion, the compensation of periodic respiratory disturbance to posture is less effective when the respiratory demand increases. The patterns of muscle activity suggest that abdominal muscles are controlled differentially and that their functional coordination is dependent on the level of ventilation, reinforcing the existence of functional links between respiratory centres and the postural control system. The present study was focused on young healthy adults. Changes in respiratory and postural conditions tested on various populations 
for which: (i) the neuromuscular system's functional status is impaired; or (ii) respiratory resistance or postural instability are increased, would allow a better understanding of the coordination between the respiratory and postural components of the abdominal muscles.

\section{References}

[1] Bouisset S, Do MC. Posture, dynamic stability, and voluntary movement. Clin Neurophysiol 2008;38:345-62.

[2] Hodges PW, Gurfinkel VS, Brumagne S, Smith TC, Cordo PC. Coexistence of stability and mobility in postural control: evidence from postural compensation for respiration. Exp Brain Res 2002;144:293-302.

[3] David P, Laval D, Terrien J, Petitjean M. Postural control and ventilatory drive during voluntary hyperventilation and carbon dioxide rebreathing. Eur J Appl Physiol 2012;112:14554.

[4] Urquhart DM, Hodges PW, Story IH. Postural activity of the abdominal muscles varies between regions of these muscles and between body positions. Gait Posture 2005;22:295-301. [5] De Troyer A. Mechanical role of the abdominal muscles in relation to posture. Respir Physiol 1983;53:341-53.

[6] Hodges P. Abdominal mechanism and support of the lumbar spine and pelvis. In: Therapeutic Exercise for Lumbopelvic Stabilization, Edinburgh: Churchill Livingstone; 2004, p. $31-57$.

[7] Horak FB, Nashner LM. Central programming of postural movements: adaptation to altered support-surface configurations. J Neurophysiol 1986;55:1369-81.

[8] Hodges PW, Richardson CA. Contraction of the abdominal muscles associated with movement of the lower limb. Phys Ther 1997;77:132-42. 
[9] De Troyer A, Loring SH. Action of the respiratory muscles. In: Macklem PT, Mead J, editors. Handbook of Physiology: The Respiratory System, Bethesda: American Physiological Society; 1986, p. 443-61.

[10] Campbell EJ, Green JH. The behaviour of the abdominal muscles and the intraabdominal pressure during quiet breathing and increased pulmonary ventilation; a study in man. J Physiol 1955;127:423-6.

[11] Abraham KA, Feingold H, Fuller DD, Jenkins M, Mateika JH, Fregosi RF. Respiratoryrelated activation of human abdominal muscles during exercise. J Physiol 2002;541:653-63.

[12] Henke KG, Sharratt M, Pegelow D, Dempsey JA. Regulation of end-expiratory lung volume during exercise. J Appl Physiol (1985) 1988;64:135-46.

[13] Hodges P, Saunders S. Coordination of the respiratory and locomotor activities of the abdominal muscles during walking in humans. In: Proceedings of International Union of Physiological Sciences; 2001.

[14] Saunders SW, Rath D, Hodges PW. Postural and respiratory activation of the trunk muscles changes with mode and speed of locomotion. Gait Posture 2004;20:280-90.

[15] Vuillerme N, Hintzy F. Effects of a $200 \mathrm{~W}-15$ min cycling exercise on postural control during quiet standing in healthy young adults. Eur J Appl Physiol 2007;100:169-75.

[16] David P, Mora I, Terrien J, Lelard T, Petitjean M. Leg muscles activities during hyperventilation following a cycling exercise. Electromyogr Clin Neurophysiol 2010;50:3945.

[17] European Respiratory Society. Volumes pulmonaires et débits ventilatoires forcés. Rev Mal Respir 2001;18:S13-52.

[18] Hermens HJ, Freriks B, Disselhorst-Klug C, Rau G. Development of recommendations for SEMG sensors and sensor placement procedures. J Electromyogr Kinesiol 2000;10:36174. 
[19] Drake JD, Callaghan JP. Elimination of electrocardiogram contamination from electromyogram signals: An evaluation of currently used removal techniques. J Electromyogr Kinesiol 2006;16:175-87.

[20] Beith ID, Harrison PJ. Stretch reflexes in human abdominal muscles. Exp Brain Res 2004;159:206-13.

[21] Kenyon CM, Cala SJ, Yan S, Aliverti A, Scano G, Duranti R, et al. Rib cage mechanics during quiet breathing and exercise in humans. J Appl Physiol (1985) 1997;83:1242-55.

[22] Hodges PW, Cresswell AG, Thorstensson A. Intra-abdominal pressure response to multidirectional support-surface translation. Gait Posture 2004;20:163-70.

[23] Kantor E, Poupard L, Le Bozec S, Bouisset S. Does body stability depend on postural chain mobility or stability area? Neurosci Lett 2001;308:128-32.

[24] Hamaoui A, Do Mc, Poupard L, Bouisset S. Does respiration perturb body balance more in chronic low back pain subjects than in healthy subjects? Clin Biomech (Bristol, Avon) $2002 ; 17: 548-50$.

[25] Hodges PW, Heijnen I, Gandevia SC. Postural activity of the diaphragm is reduced in humans when respiratory demand increases. J Physiol 2001;537:999-1008.

[26] Bouisset S, Le Bozec S. Posturo-kinetic capacity and postural function in voluntary movements. In: Latash ML, editor. Progress in motor control, vol 2: Structure-function relations in voluntary movements, Pennstate: Human kinetics; 2002, p.25-52.

[27] Smith MD, Russell A, Hodges PW. Disorders of breathing and continence have a stronger association with back pain than obesity and physical activity. Aust J Physiother 2006;52:11-6.

[28] David P, Mora I, Pérot C. Neuromuscular efficiency of the rectus abdominis differs with gender and sport practice. J Strength Cond Res 2008;22:1855-61. 
[29] Mouchnino L, Aurenty R, Massion J, Pedotti A. Coordination between equilibrium and head-trunk orientation during leg movement: a new strategy build up by training. J Neurophysiol 1992;67:1587-98.

[30] Manor BD, Hu K, Peng CK, Lipsitz LA, Novak V. Posturo-respiratory synchronization: effects of aging and stroke. Gait Posture 2012;36:254-9. 


\section{Figure captions}

Fig. 1. Experimental set-up for the measurement of cardiorespiratory, electromyographic, and postural sway variables during bipedal standing. $\dot{\mathbf{Q}}$, oxygen uptake; $\dot{\mathrm{V}}_{\mathrm{E}}$, minute ventilation; $\mathrm{V}_{\mathrm{T}}$, tidal volume; $f_{\mathrm{R}}$ breathing frequency; $\mathrm{HR}$, heart rate; RA, rectus abdominis; OE, obliquus externus abdominis; OI, obliquus internus abdominis; $\mathrm{CoP}_{\mathrm{A}-\mathrm{P}}$, anteroposterior displacement of the centre of pressure.

Fig. 2. Electromyographic patterns of the right abdominal muscles and anteroposterior displacement of the centre of pressure $\left(\mathrm{CoP}_{\mathrm{A}-\mathrm{P}}\right)$ recorded in postural test just after $\left(\mathrm{PEPT}_{0}\right)$ an incremental cycling exercise for one subject. The electromyograms and the anteroposterior displacement of the CoP were averaged to generate typical pattern of abdominal muscle activity and mechanical tracing over an average respiratory cycle.

Fig. 3. Obliquus externus abdominis (OE), obliquus internus abdominis (OI) and rectus abdominis (RA) EMG activities measured in postural tests following an incremental cycling exercise. In panel A, EMGs were quantified by their RMSs and expressed as percentages of the baseline values obtained in the pre-effort postural test (dotted line). In panel B, EMGs were measured in postural test just after $\left(\mathrm{PEPT}_{0}\right)$ an incremental cycling exercise and were quantified by their RMSs and expressed as percentages of the baseline values obtained in the pre-effort postural test (dotted line) over the entire respiratory cycle (black bars), over the expiratory phase (light grey bars) and over the inspiratory phase (dark grey bars) of breathing cycle. Means plus one standard deviation are represented. Means plus one standard deviation are represented. * and $* *$ denote significant differences at $p<0.05$ and $p<0.01$, respectively. 
Fig. 4. Simultaneous recordings of respiration (inspiratory phase: low-magnitude pulse signal) and raw electromyograms of the right abdominal muscles in postural test before (panel A) and just after (panel B) an incremental cycling exercise for one subject. 


\section{Tables}

Table 1. Cardiorespiratory $\left(\dot{\mathrm{V}}_{2}, \dot{\mathrm{V}}_{\mathrm{E}}, \mathrm{V}_{\mathrm{T}}, \mathrm{V}_{\mathrm{T}} / \mathrm{VC}, f_{\mathrm{R}}, \mathrm{HR}\right)$ and postural sway $(\mathrm{SP}, \Delta \mathrm{x})$ parameters measured in postural tests before (pre-effort test), just after ( $\left.\mathrm{PEPT}_{0}\right)$ and over the next 4 minutes following $\left(\mathrm{PEPT}_{1}\right.$ to $\left.\mathrm{PEPT}_{4}\right)$ an incremental cycling exercise (mean \pm standard deviation). $*$ and $* *$ denotes significant differences between the pre-effort postural test and the post-effort postural test at $p<0.05$ and $p<0.01$, respectively.

\begin{tabular}{|c|c|c|c|c|c|c|}
\hline & Pre-effort test & $\mathrm{PEPT}_{0}$ & $\mathrm{PEPT}_{1}$ & $\mathrm{PEPT}_{2}$ & $\mathrm{PEPT}_{3}$ & $\mathrm{PEPT}_{4}$ \\
\hline$\dot{\mathrm{V}} \mathrm{O}_{2} \quad\left(\mathrm{~L}_{\mathrm{STPD}} \cdot \mathrm{min}^{-1}\right)$ & $0.36 \pm 0.05$ & $3.43 \pm 0.70^{* *}$ & $2.35 \pm 0.41 * *$ & $1.19 \pm 0.2 * *$ & $0.77 \pm 0.14 * *$ & $0.66 \pm 0.16^{* *}$ \\
\hline$\dot{\mathrm{V}}_{\mathrm{E}}\left(\mathrm{L}_{\mathrm{BTPS}} \cdot \mathrm{min}^{-1}\right)$ & $12.8 \pm 1.4$ & $102.8 \pm 19.1 * *$ & $71.0 \pm 11.2 * *$ & $47.4 \pm 8.5^{* *}$ & $33.9 \pm 4.7 * *$ & $28.4 \pm 5.5^{* *}$ \\
\hline $\mathrm{V}_{\mathrm{T}}\left(\mathrm{L}_{\mathrm{BTPS}}\right)$ & $0.75 \pm 0.10$ & $2.70 \pm 0.65^{* *}$ & $2.40 \pm 0.61 * *$ & $1.95 \pm 0.43 * *$ & $1.47 \pm 0.28 * *$ & $1.28 \pm 0.30 * *$ \\
\hline $\mathrm{V}_{\mathrm{T}} / \mathrm{VC}(\%)$ & $14.5 \pm 1.9$ & $51.5 \pm 9.0 * *$ & $45.6 \pm 8.4 * *$ & $37 \pm 5^{* *}$ & $27.9 \pm 3.4^{* *}$ & $24.3 \pm 4.4 * *$ \\
\hline$f_{\mathrm{R}}(\mathrm{Hz})$ & $0.29 \pm 0.05$ & $0.66 \pm 0.19 * *$ & $0.52 \pm 0.15^{* *}$ & $0.43 \pm 0.15^{* *}$ & $0.4 \pm 0.07 * *$ & $0.38 \pm 0.08^{* *}$ \\
\hline $\operatorname{HR}\left(\right.$ b. $\left.\min ^{-1}\right)$ & $83.9 \pm 10.5$ & $186.2 \pm 9.8^{* *}$ & $165.6 \pm 13.5^{* *}$ & $140.7 \pm 14.8^{* *}$ & $128.5 \pm 15.8^{* *}$ & $123.6 \pm 15.2^{* *}$ \\
\hline $\mathrm{SP}(\mathrm{mm})$ & $164.1 \pm 30.7$ & $365.8 \pm 104.9 * *$ & $256.5 \pm 76.2 * *$ & $222.1 \pm 63.4 * *$ & $202.5 \pm 46.4^{*}$ & $205.6 \pm 53.8^{*}$ \\
\hline$\Delta \mathrm{x}(\mathrm{mm})$ & $3.4 \pm 0.8$ & $5.9 \pm 1.6^{* *}$ & $4.5 \pm 0.9 * *$ & $4.0 \pm 0.8$ & $3.8 \pm 1.0$ & $4.0 \pm 1.3$ \\
\hline
\end{tabular}




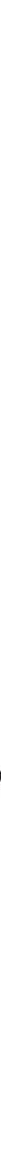


Expiratory phase

Inspiratory phase
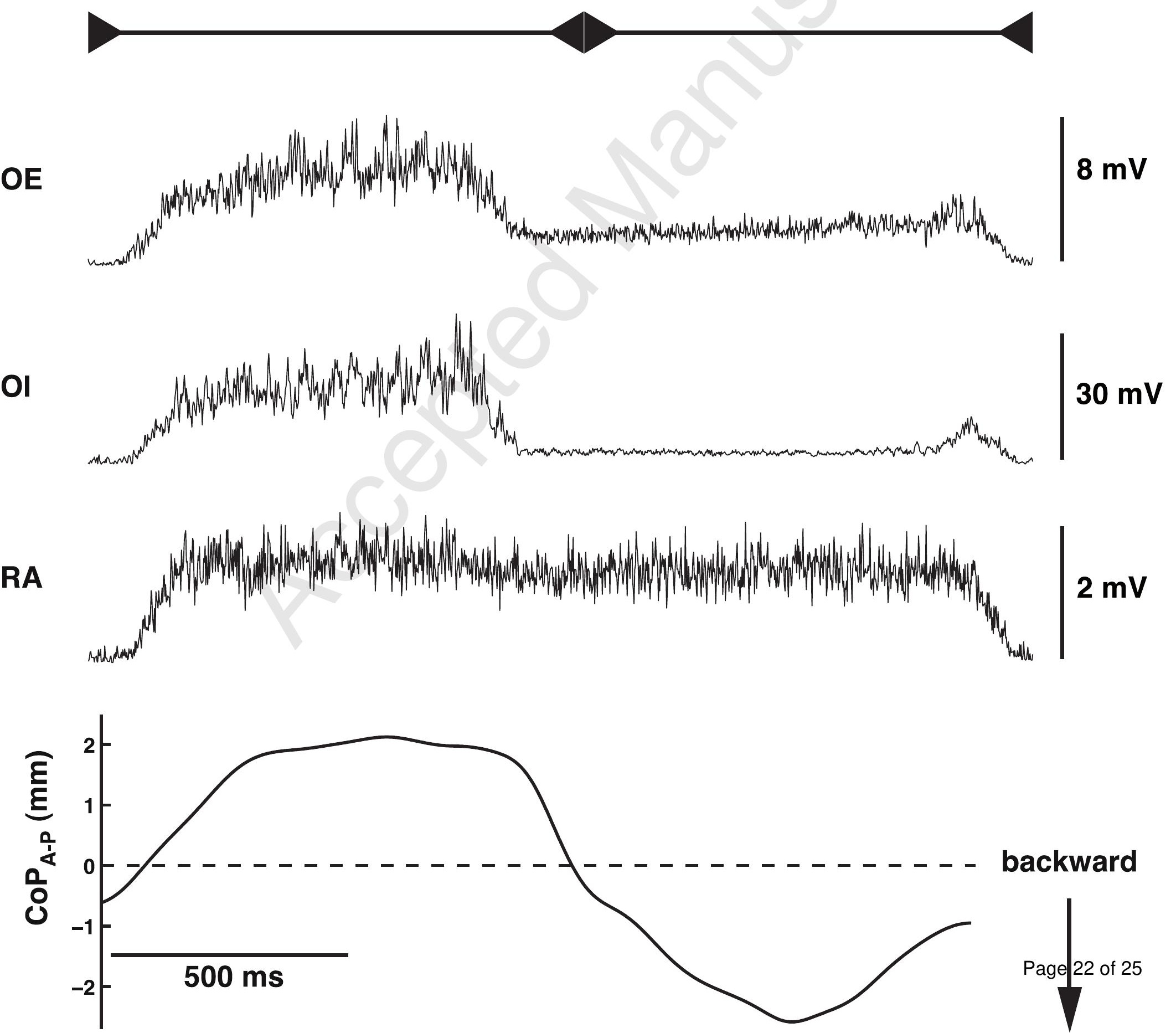
OE

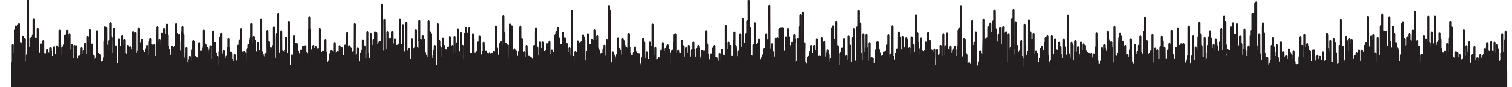
$10 \mu \mathrm{V}$

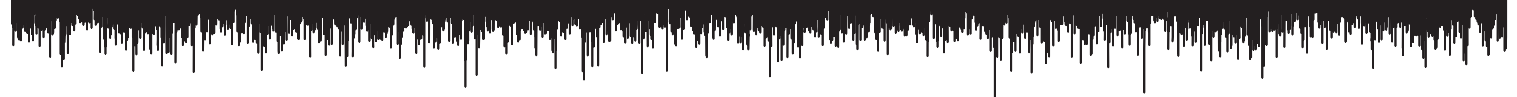

이

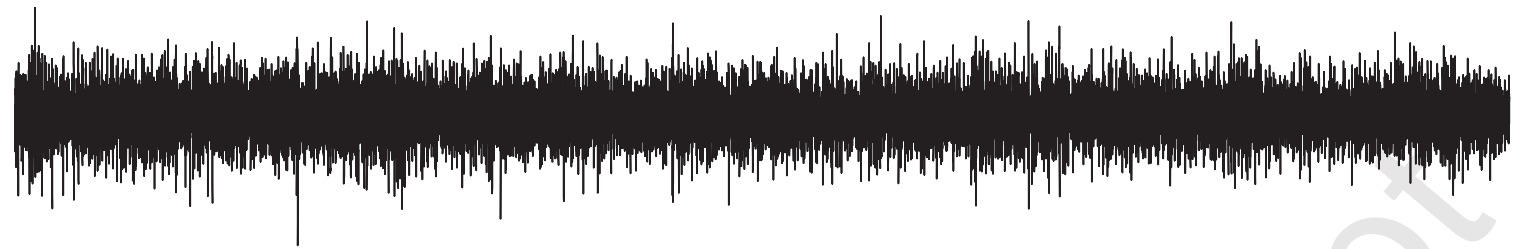
$20 \mu \mathrm{V}$

RA

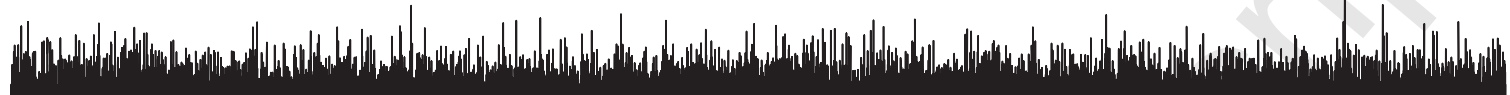

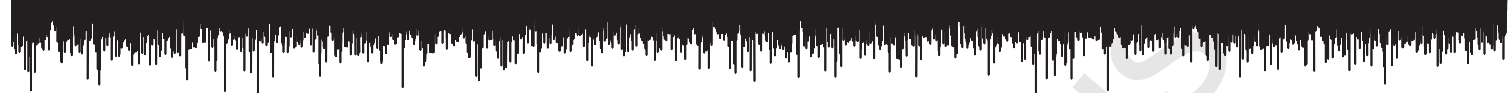

\section{Exp}

\section{Respiration}

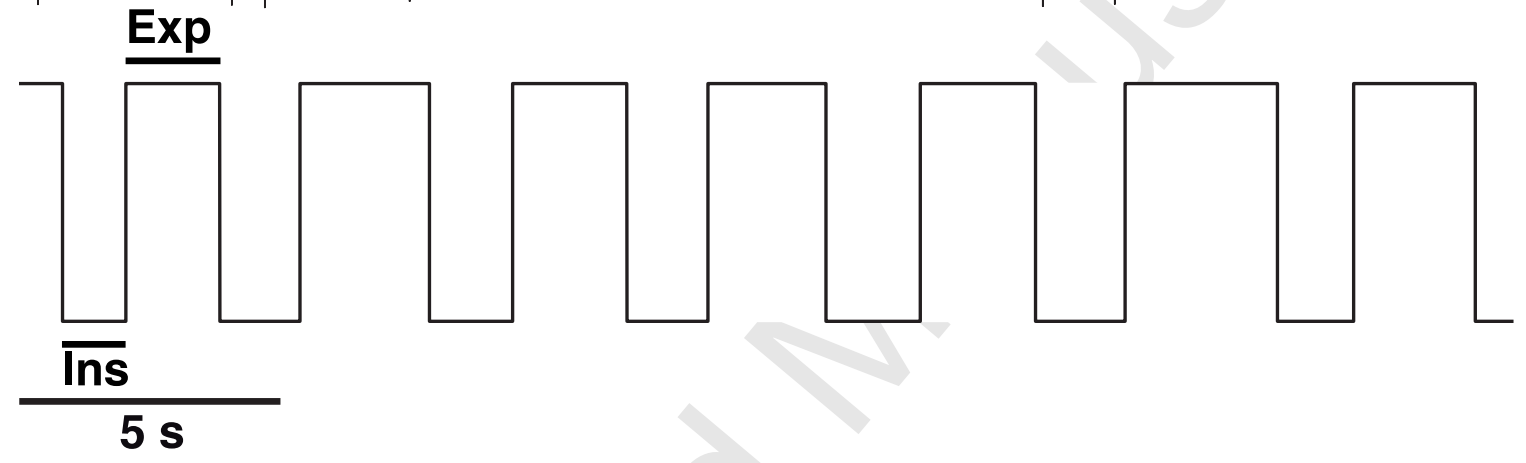

B

OE

RA

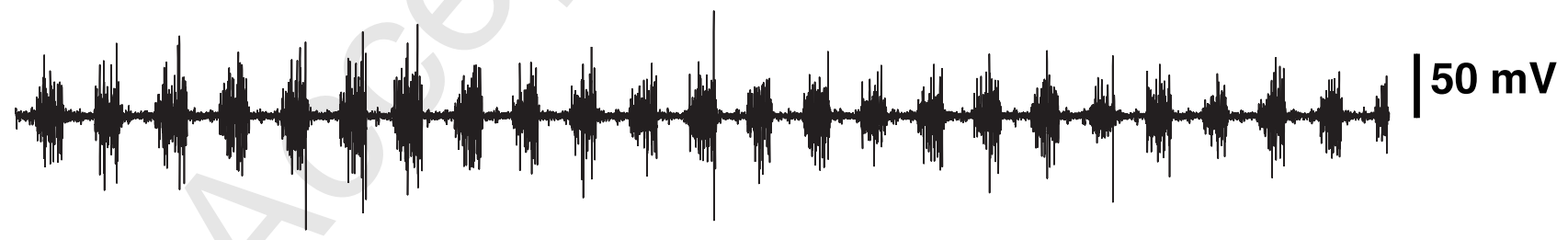

\section{Respiration}

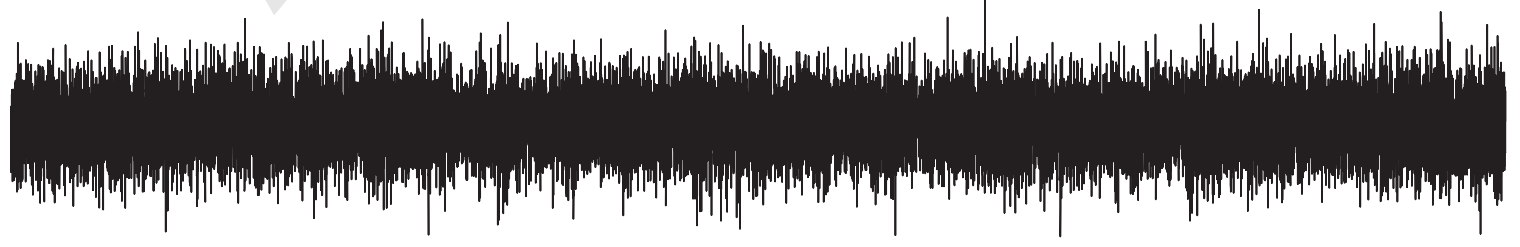

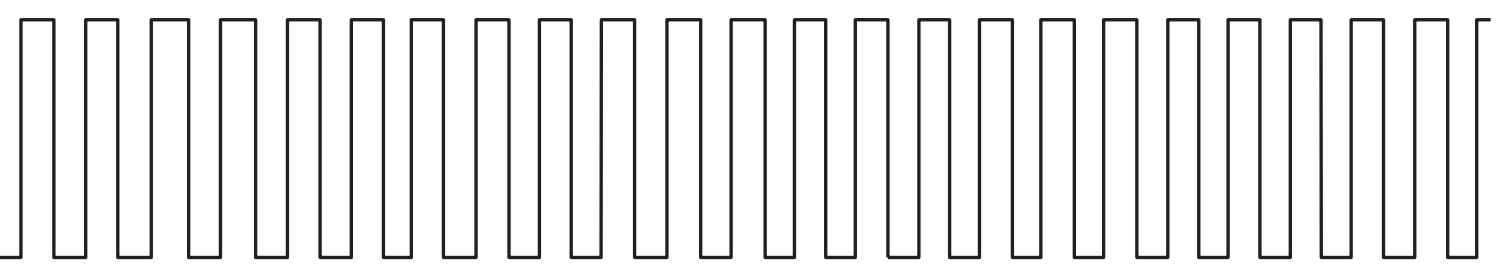




\section{Highlights}

- Post-exercise hyperventilation involves periodic movement of the CoP in phase with respiration.

- EMG activities of OE and OI were prominent during expiration.

- OI was silent during inspiration.

- OE and RA were activated during both expiration and inspiration.

- Functional coordination of abdominal muscles is dependent on the level of ventilation. 